$12-2019$

\title{
Eel fish bite: An impending emergency in Arabian sea
}

Sadia Zafar

Zafar Fatmi

Follow this and additional works at: https://ecommons.aku.edu/pakistan_fhs_mc_chs_chs

Part of the Community Health and Preventive Medicine Commons 


\section{LETTER TO THE EDITOR}

\section{Eel fish bite: an impending emergency in Arabian sea}

Sadia Zafar, ${ }^{1}$ Zafar Fatmi²

Madam, we report a case of a 14 year old boy who suffered an eel fish bite, receiving a gaping wound at the right wrist. The bite was severe enough to receive emergency care with many stitches. The patient was on a picnic with the family and enjoying the sea shore at about 2-feet shallow water of Arabian Sea (Hawkes bay, Karachi, Pakistan) on October, 2018. While playing in the water, by chance, the boy grasped the eel fish by the tail and probably in desperation to free itself, it bit him on the same hand. The blood started oozing immediately and the boy was taken to the nearby general practitioner. Following extensive irrigation of the wound with normal saline and administration of local anaesthesia, laceration repair was done with sutures. The patient was offered systematic analgesics but no tetanus toxoid was given. He was sent back home with oral antibiotics (coverage from gram negative and gram positive bacteria) and analgesics. We could not find any report of eel fish bite in the literature. ${ }^{1}$ However; review suggested that several species of eel fish are poisonous, probably three times as poisonous as viper snake. The patient was followed for four days and reported no complications.

Disclaimer: None to declare.

Conflict of Interest: None to declare.

${ }^{1}$ Community Health Sciences, Aga Khan University, Karachi, 2Independent Consultant, Karachi, Pakistan.

Correspondence: Zafar Fatmi. Email: zafar.fatmi@aku.edu

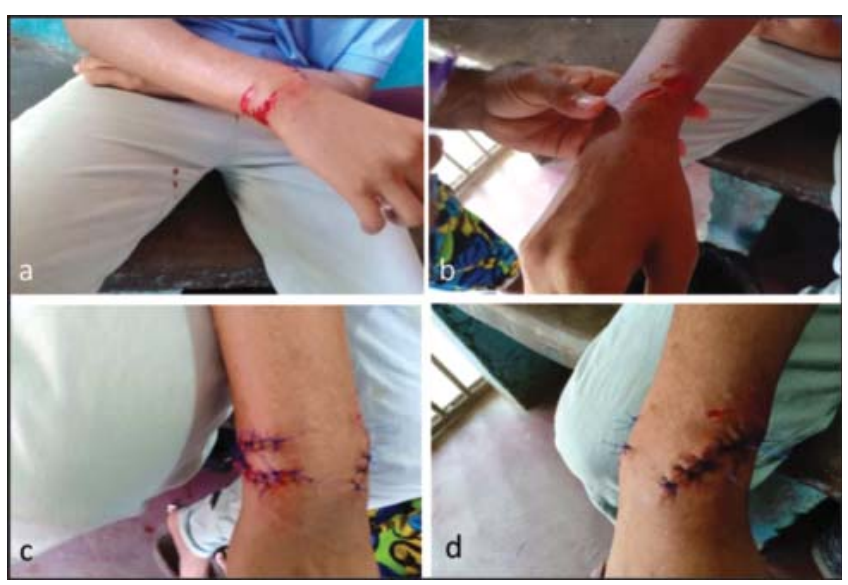

Figure-1: Right wrist wound by eel fish bite, before $(a, b)$ and after $(c, d)$ the sutures.

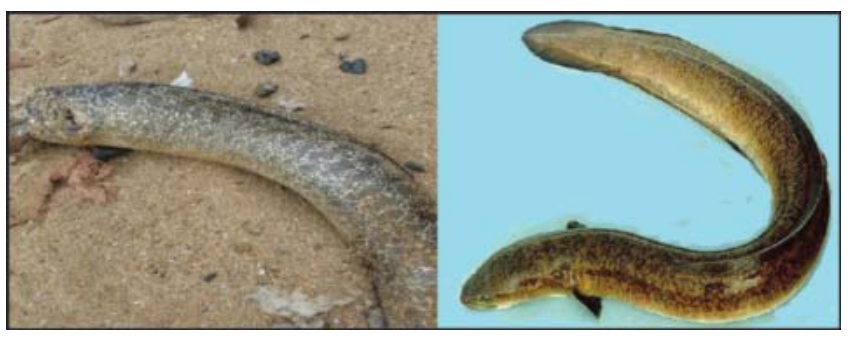

Figure-2: Eel fish of Arabian Sea (one found on the beach).

Funding Sources: None to declare.

\section{References}

1. Frederich W. Tesch. In: John Thorpe, eds. The Eel. UK: John Wiley \& Sons, 2008; pp 416.

DOI:10.5455/JPMA.25623. 